Article

\title{
Genetic aspects of primary headaches in Siberia (Russia)
}

\author{
Aleksey V. Kondratiev ${ }^{1}$, Natalia A. Shnayder ${ }^{1,2^{*}}$, Andrey V. Shulmin ${ }^{3}$, Diana V. Dmitrenko ${ }^{1^{*}}$, Vera V. Trefilova ${ }^{2,4^{*}}$, \\ Svetlana N. Zobova ${ }^{1}$, Elena A. Kantimirova ${ }^{1}$, Marina M. Petrova ${ }^{1}$, Daria S. Kaskaeva ${ }^{1}$, Elena E. Vaiman ${ }^{2}$ and Regina \\ F. Nasyrova ${ }^{*}$
}

Citation: Kondratiev, A.V.;

Shnayder, N.A.; Shulmin, A.V.; Dmitrenko, D.V.; Trefilova, V.V.; Zobova, S.N.; Kantimirova, E.A.; Petrova, M.M.; Kaskaeva, D.S.;

Vaiman, E.E., Nasyrova, R.F. Genetic aspects of primary headaches in $\mathrm{Si}$ beria (Russia). Personalized Psychiatry and Neurology 2021, 1 (1): 54-63

Chief Editor: Nikolaj G. Neznanov, D Med Sci, Professor

Received: 30 April 2021 Accepted: 12 May 2021 Published: 14 May 2021

Publisher's Note: V. M. Bekhterev NMRC PN stays neutral with regard to jurisdictional claims in published maps and institutional affiliations.

Copyright: (c) 2021 by the authors.
1 V. F. Voino-Yasenetsky Krasnoyarsk State Medical University, 660022, Krasnoyarsk, Russia;

2 V. M. Bekhterev National Medical Research Center for Neurology and Psychiatry, 192019, Saint-Petersburg, Russia;

3 Vitebsk State Medical University, 210009, Vitebsk, Belarus;

4 The Hospital for War Veterans, 193079, St. Petersburg, Russia.

* Correspondence: naschnaider@yandex.ru (N.A.S.); mart2802@yandex.ru (D.V.D.); vermutdoc@gmail.com (V.V.T); nreginaf77@gmail.com (R.F.N.); Tel.: +7-(812)-670-02-20 (N.A.S.), (R.F.N.); +7-(391)-201-65-24 (D.V.D.); +7-(812)-670-89-37 (V.V.T).

\begin{abstract}
Primary headaches are common neurological problem in the world. Migraine (M) and tension type headache (TTH) are the leaders in the structure of primary headaches in the population; (1) Background: The study of the association of single nucleotide variants (SNVs) of MTHFR (methylenetetrahydrofolate reductase) and HTR2C (5-Hydroxytryptamine Receptor 2C) genes with M and TTH development in the European population in Siberia (Russia); (2) Methods: 192 adults were examined: $82(42.7 \%)$ males and $110(57.3 \%)$ females. Control group: 81 healthy adults, median age 49.5 [36; 59] years; 53 (66.7\%) males and 27 (33.3\%) females. Headache group consisted of 111 patients with primary headache, median age $54[45 ; 64]$ years, including two subgroups: subgroup 1 (M) of 39 patients; subgroup 2 (TTH) of 72 patients. Carriage of alleles and genotypes rs1801133 and rs1801131 of the MTHFR gene and rs6318 of the HTR2C gene was determined using PCR-RT by TaqMan allelic discrimination technology; (3) Results: A statistically significant association of the carriage of the A allele rs1801133 of the MTHFR gene with the formation of M ( $p=0.025)$ and TTH $(p=0.022)$, as well as the GA genotype with the development of TTH $(p=0.024)$ was revealed. Carriage of the G allele and the TG and GG genotypes of the MTHFR gene, associated with a decreased activity of the MTHFR enzyme, does not affect the development of primary headache. A statistically significant association was revealed between the carriage of the heterozygous GC genotype (rs6318) of the HTR2C gene and the formation of M ( $\mathrm{p}=0.013)$; (4) Conclusions: Carriage of the A allele (OR 1.77; 95\% CI 1.09-2.89) and the GA genotype (OR 2.24; 95\% CI 1.17-4.29) rs1801133 of the MTHFR gene is a risk factor for the development of TTH $(\mathrm{p}<0.05)$. Carriage of the A allele rs1801133 of the MTHFR gene is a risk factor for the development of M (OR 1.97; 95\% CI 1.08-3.57; $\mathrm{p}<0.05)$. Carriage of the variant G allele and rs1801131 GT and GG genotypes associated with reduced activity of the MTHFR enzyme does not affect the development of primary headache. In the control group, the prevalence of the $\mathrm{T}$ allele associated with normal enzymatic activity was noted $(p=0.024)$. Carriage of the heterozygous genotype CG SNV rs6318 of the HTR2C gene increases the risk of developing migraine by 3.6 times.
\end{abstract}

Keywords: headache; genetics; migraine; tension type headache; MTHFR; HTR2C.

\section{Introduction}

Headache is an important medical and social problem. The incidence of episodic headache in Russia and abroad reaches 93\%, while frequent headache is $50-60 \%$ [1]. Primary headache $(\mathrm{PH})$ occurs as a result of a combination of environmental factors and individual characteristics of the organism, among which genetic predisposition plays an 
important role [2]. Genetics remains the least studied component of the pathogenesis of $\mathrm{PH}$. Reproduction of studies in other ethnic populations is generally accepted evidence of the association of a genetic marker with a disease. The most common forms of $\mathrm{PH}$ include migraine $(\mathrm{M})$, tension type headache $(\mathrm{TTH})$, and cluster headache.

According to I. Rainero et al. (2012), the main genes involved in the pathogenesis of PH are: MTHFR (encodes methylene tetrahydrofolate reductase, an intracellular enzyme that plays a key role in the metabolism of folate and methionine), KCNK18 (encodes a potassium channel activator protein), TRPV1, TRPV3 (encodes in receptors, which are one of the most important integrators of painful and inflammatory stimuli, which allows us to consider them as a promising therapeutic target in the treatment of painful conditions) and HCRTR (encodes a receptor for hypocretins - neuropeptides synthesized in the hypothalamus) [3].

According to X. Li et al. (2014), the genes CALCA (encodes calcitonin, which affects the concentration of calcium and phosphate in the blood), ESR1 (encodes the estrogen receptor- $\alpha$, involved in the regulation of sexual development, gametogenesis, growth and maintenance of the skeleton, nervous systems and cardiovascular function), MTHFR are also associated with $\mathrm{PH}$ [4]. The role of the TRPV gene in the pathogenesis of $\mathrm{PH}$ is confirmed by the studies of M. Dux et al. [5].

Authors of many decent publications claim the connection between frequency of headache attacks, their intensity as well as chronization tendency and the serotonin blood level $[6,7,8]$. Another matter of interest is the serotonin perception level of specialized receptors $[9,10]$. Still, the predisposition of serotonin genes' polymorphisms' carriers to primary headaches remains insufficiently studied. Y Yucel, et al, 2016 [11] focused their research on polymorphisms of genes 5-HT1A, 5-HT1B, 5-HT2A and 5HT2C, authors have performed the analysis on carriers of rs1200060, rs1228814, rs6313, rs6311, rs6314, rs6318, rs3813929 and rs518147 polymorphisms. The one and only statistically significant connection was found between migraine diagnosis and polymorphism rs3813929 of 5-HTR2C gene. On the other hand, A.Oterino, et al, 2007 [12] haven't found any connection at all between Cys23Ser polymorphism of HTR2C gene and migraine attacks in Spanish sample.

In general, genetic studies on the role of single nucleotide variants (SNVs) of various metabolic genes and receptors are continuing and are undoubtedly relevant from the standpoint of preventive and personalized medicine for identifying patients at risk.

\subsection{Migraine}

Of all types of $\mathrm{PH}, \mathrm{M}$ is the most studied from the point of view of genetics. It is known that the presence of a positive family history in an individual increases the risk of M: if the mother is sick - up to $70 \%$, if the father is sick - up to $30 \%$, and if both parents are sick - up to $90 \%$ [13]. In turn, of all types of M, genotyping of familial hemiplegic migraine (FHM) was performed most often. Turning to the history of studies of the genetics of $\mathrm{M}$ in particular and PH in general, it can be noted that in $1993 \mathrm{~A}$. Joutel et al. first identified the locus responsible for the development of FHM on chromosome 19 [14]. In 1996 R. Ophoff et al. described the involvement of the CACNA1A gene encoding the $\alpha 1-$ subunit of calcium channels in the pathogenesis of FHM. The discovery of mutations in the CACNA1A gene in families with FHM is associated with a new understanding of the pathophysiology of this disease [15]. Research by A. May et al. (1995) [16] and G. Terwindt et al. (2001) [17] identified the importance of chromosome 19p13 in the etiology of migraine, especially migraine with aura. E.E. Kors et al. (2004) in addition to the $C A C N A 1 A$ gene on chromosome 19 previously identified in type 1 FHM showed the 
significance of the ATP1A2 gene in type $2 \mathrm{FHM}$, which encodes an integral membrane protein responsible for the creation and maintenance of electrochemical gradients of $\mathrm{Na}$ ions and $\mathrm{K}$ across the membrane, which is essential for electrical excitability of nerves and muscles [18]. M. Russell et al. (2011) confirms the presence of a mutation in the CACNA1A gene on chromosome 19p13, which encodes the state of cerebral specific P / Q-type calcium channels in patients with FHM. The ATP1A2 gene, associated with the development of type $2 \mathrm{FHM}$, is localized on chromosome 1q23. Type 3 FHM revealed a mutation in the SCN1A gene encoding the $\alpha 1$ subunit of sodium channels located on the short arm of chromosome 2 at the 2q24 locus [19]. Candidate genes for other types of migraine are the $S L C 6 A 3$ gene, a regulator of dopaminergic neurotransmission; gene MTHFR - methylenetetrahydrofolate reductase; gene TNF- $\alpha$ - tumor necrosis factor- $\alpha$, excess production of which causes hemodynamic disorders and cytotoxic effect [13]. S.V. Kopishinskaya et al. (2015) identified SNV associations of the CACNA1A, ATP1A2, SCN1A genes with FHM in Russian patients [20]. The review by A. Ducros (2013) indicates the following genes associated with the development of FHM: CACNA1A, FHM1 (encodes calcium channels), ATP1A2, FHM2 (encodes potassium channels), SCN1A, FHM3 (encodes sodium channels), PRRT2 (encodes axonal protein). Studies of migraine in cell and animal models have shown that mutations in the CACNA1A and ATP1A2 genes contribute to the onset of cortical spreading depression, a mechanism underlying the migraine aura [21].

\subsection{Tension Type Headache}

M. Russell et al. (2007) [22] examined Norwegians (2,437 monozygotic twins, 2,720 dizygotic twins of the same sex, and 2203 dizygotic twins of the opposite sex). The heritability of TTH was found in $48 \%$ of men and $44 \%$ of women. In another work by M. Russell (2007) it was shown that the genetic factor plays a significant role in chronic TTH and an insignificant role in episodic headache [23]. C. Gaul et al. (2016) report on the role of the CGRP gene in the pathogenesis of tension hypertension [24]. T. Edgnülü et al. (2014) studied SNVs of the MAOA gene promoter and 13 introns of the MAOB gene (encodes monoamine oxidase $B$, which regulates phenylethylamine and dopamine metabolism) in a population in Turkey. Comparison of 120 patients with TTH and 168 unrelated healthy volunteers did not reveal statistically significant differences [25].

The purpose is the study of the association of SNVs of MTHFR and HTR2C genes (Fig. 1) with M and TTH development in European population in Siberia (Russia).

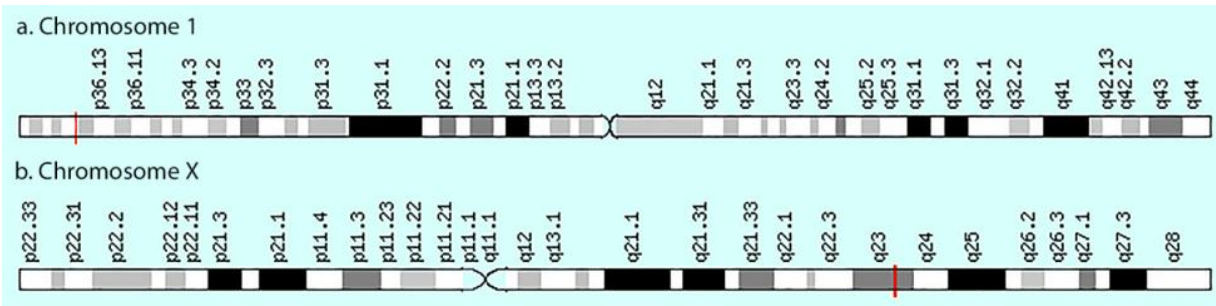

Figure 1. Chromosomal loci of MTHFR (a) and HTR2C (b) genes

\section{Materials and Methods}

We examined 192 adults of European descent permanently residing in the Siberian Federal District of the Russian Federation (Siberia), including: 82 (42.7\%) males and 110 (57.3\%) females. The study was approved by the Ethics Committee of the V.F. VoinoYasenetsky Krasnoyarsk State Medical University. The work was carried out within the framework of comprehensive research on the topic No. 210-16 "Epidemiological, genetic and neurophysiological aspects of diseases of the nervous system (central, peripheral 
and vegetative) and preventive medicine" (state registration number 0120.0807480). Patients with $\mathrm{PH}$ and healthy volunteers were included in the study after signing a voluntary informed consent. Patients and healthy volunteers were not rewarded for participating in this study. Researchers were not rewarded for doing this study.

Patients were included in the study according to the diagnostic criteria of the international classification of headache - 3 (ICHD-3) (Tab. 1). Diagnostic criteria for M: A. At least five attacks1 fulfilling criteria B-D: B. Headache attacks lasting 4-72 h (untreated or unsuccessfully treated); C. Headache has at least two of the following four characteristics: 1. unilateral location; 2. pulsating quality; 3. moderate or severe pain intensity; 4. aggravation by or causing avoidance of routine physical activity (eg, walking or climbing stairs); D. During headache at least one of the following: 1. nausea and/or vomiting; 2. photophobia and phonophobia; E. Not better accounted for by another ICHD-3 diagnosis. Diagnostic criteria for TTH: A. At least 10 episodes of headache occurring on $<1$ day/month on average ( $<12$ days/year) and fulfilling criteria B-D: B. Lasting from 30 minutes to 7 days; $C$. At least two of the following four characteristics: 1 . bilateral location; 2. pressing or tightening (non-pulsating) quality; 3. mild or moderate intensity; 4. not aggravated by routine physical activity such as walking or climbing stairs; D. Both of the following: 1. no nausea or vomiting; 2 . no more than one of photophobia or phonophobia; E. Not better accounted for by another ICHD-3 diagnosis.

Table 1. Diagnostic criteria for primary headaches [26].

\begin{tabular}{|c|c|}
\hline Migraine & Tension type headache \\
\hline $\begin{array}{l}\text { A. At least five attacks1 ful- } \\
\text { filling criteria B-D: } \\
\text { B. Headache attacks lasting } \\
\text { 4-72 hr (un-treated or unsuc- } \\
\text { cessfully treated); } \\
\text { C. Headache has at least two } \\
\text { of the following four charac- } \\
\text { teristics: } \\
\text { 1. unilateral location; } \\
\text { 2. pulsating quality; } \\
\text { 3. moderate or severe pain } \\
\text { intensity; } \\
\text { 4. aggravation by or causing } \\
\text { avoidance of routine physica } \\
\text { activity (eg, walk-ing or } \\
\text { climbing stairs); } \\
\text { D. During headache at least } \\
\text { one of the following: } \\
\text { 1. nausea and/or vomiting; } \\
\text { 2. photophobia and phono- } \\
\text { phobia; } \\
\text { E. Not better accounted for } \\
\text { by an-other ICHD-3 diagno- } \\
\text { sis }\end{array}$ & $\begin{array}{l}\text { A. At least } 10 \text { episodes of } \\
\text { headache occurring on }<1 \\
\text { day/month on average ( }<12 \\
\text { days/year) and fulfilling cri- } \\
\text { teria B-D: } \\
\text { B. Lasting from } 30 \text { minutes to } \\
7 \text { days; } \\
\text { C. At least two of the follow- } \\
\text { ing four characteristics: } \\
\text { 1. bilateral location; } \\
2 . \text { pressing or tightening } \\
\text { (non-pulsating) quality; } \\
\text { 3. mild or moderate intensity; } \\
\text { 14. not aggravated by routine } \\
\text { physical activity such as } \\
\text { walking or climbing stairs; } \\
\text { D. Both of the following: } 1 . \\
\text { no nausea or vomiting; } 2 \text {. no } \\
\text { more than one of photopho- } \\
\text { bia or phonophobia; } \\
\text { E. Not better accounted for } \\
\text { by another ICHD-3 diagno- } \\
\text { sis. }\end{array}$ \\
\hline
\end{tabular}

Inclusion criteria for the control group: healthy adults (volunteers); age 21 and older; residents of the Siberian Federal District (Siberia); Europeans. Criteria for inclusion in the headache group: healthy adults (volunteers); age 21 and older; residents of 
the Siberian Federal District (Siberia); Europeans; verified diagnosis of PH (M or TTH). Exclusion criteria from the study: the presence of current chronic neurological pathology in the stage of exacerbation and acute neurological pathology; chronic somatic diseases in the acute stage and acute somatic diseases; infectious diseases; smoking; alcohol abuse; participation in other studies. Control group: 81 healthy adults, median age 49.5 [36; 59] years; $53(66.7 \%)$ males and $27(33.3 \%)$ females. Headache group consisted of 111 patients with primary headache, median age $54[45 ; 64]$ years, including two subgroups: subgroup 1 (M) of 39 patients; subgroup 2 (TTH) of 72 patients.

Blood sampling in a volume of 3-5 $\mathrm{ml}$ was carried out in vacuum tubes containing a $0.5 \mathrm{M}$ EDTA solution. Isolation of genomic DNA was carried out by the sorption method from $0.1 \mathrm{ml}$ of leukocyte suspension using the DNA-Sorb-B kit (103-20, AmpliPrime, Russia) according to the manufacturer's instructions. Carriage of alleles and genotypes rs1801133 and rs1801131 of the MTHFR gene, rs6318 of the HTR2C gene was determined using PCR-RT on a "Rotor-Gene 6000" thermal cycler (Corbett Life Science, Australia) using the TaqMan allelic discrimination technology and fluorescent probes ("Applied Biosystems", USA).

\section{Statistical Analysis}

Differences in categorical data were assessed using the two tailed Fisher's exact test and were considered statistically significant at $\mathrm{p} \leq 0.05$. Odds ratios (OR) and $95 \%$ confidence intervals (CI) were calculated using online calculator available at https://medstatistic.ru/calculators/calcrisk.html. The power analysis was done by "An Online Sample Size Estimator" calculator (http://osse.bii.a-star.edu.sg/calculation2.php). For SNV rs1801133 allele frequency estimation power was 0.36 and 0.35 for TTH and M, respectively; for rs1801131 it was 0.38 and 0.22 , and for rs6318 it was 0.07 and 0.06 .

\section{Results}

\subsection{MTHFR gene}

The MTHFR function promotes the homocysteine to methionine transformation. The A222V substitution in a homozygous state (TT) reduces the enzyme activity by $60 \%$, which leads to an increase in homocysteine levels and reduces the pain threshold. Significant association between the carriage of variant $\mathrm{T}$ allele (OR 1.8; 95\% CI 1.1-2.9; $\mathrm{p}=$ 0.022 ) as well as CT genotype (OR 2.2; 95\% CI 1.2-4.3; p =0.024) of SNV rs1801133 and the development of TTH was found. T allele was also significantly associated with M (OR 2.0; 95\% CI 1.1-3.6; $\mathrm{p}=0.025$ ).

There was a statistically significant association of the carriage of the variant A allele rs1801133 of the MTHFR gene with the formation of migraine $(\mathrm{p}=0.025)$ and TTH $(\mathrm{p}=$ 0.022), as well as the GA genotype with the development of TTH $(\mathrm{p}=0.024)$ (Fig. 2). 

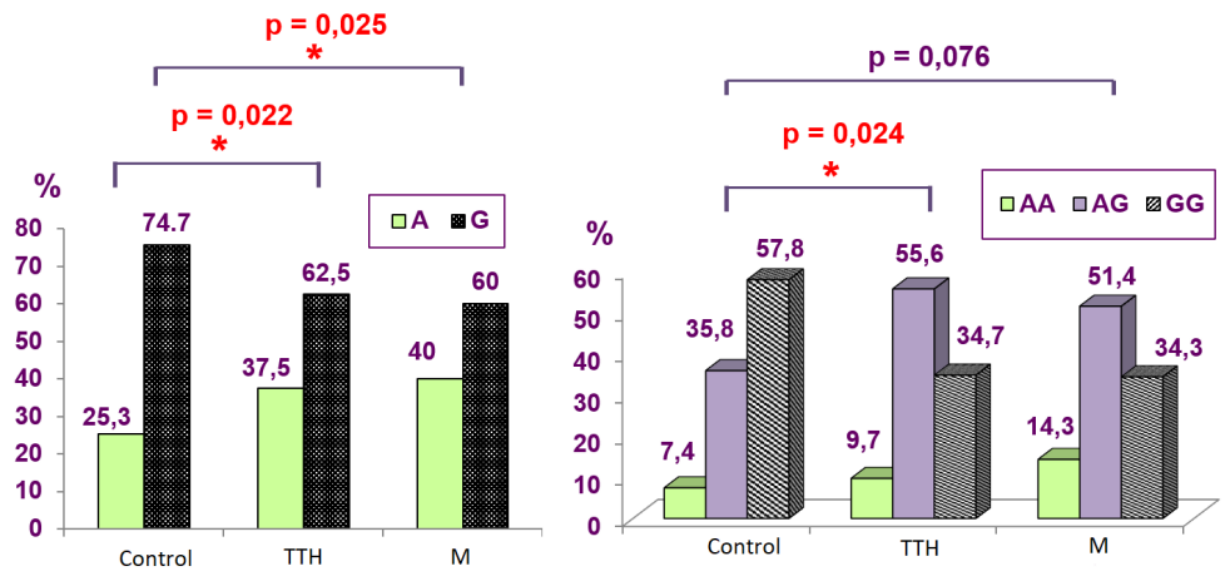

Figure 2. The frequency of carriage of alleles and genotypes rs1801133 of the MTHFR gene in patients with tension type headache (TTH) and migraine (M) vs control group.

Carriage of allele A and genotype GA rs1801133 is a risk factor for the development of TTH. Carriage of allele A is also a risk factor for the development of M (Fig. 3).

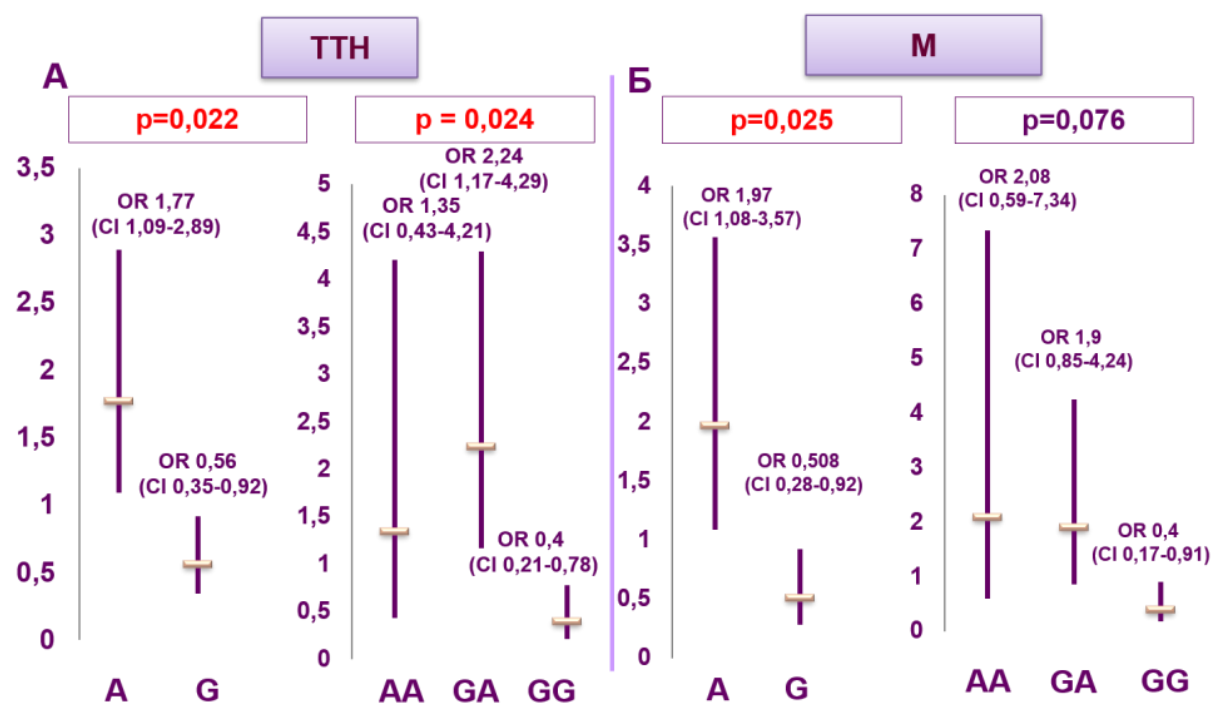

Figure 3. Odds ratio (OR) and 95\% confidence interval (CI) of the frequencies of alleles and genotypes rs1801133 (G> A) for the development of tension type headache (TTH) and migraine (M)

Carriage of the variant G allele and the TG and GG genotypes of the MTHFR gene, associated with a reduced activity of the MTHFR enzyme, does not affect the development of PH (Fig. 4). 

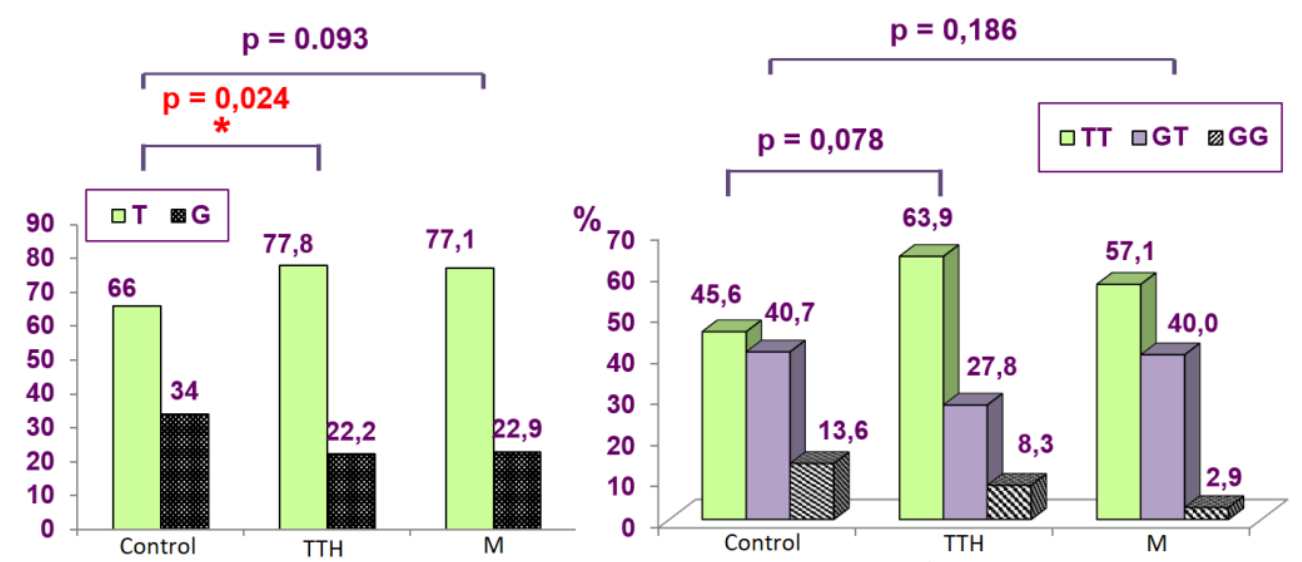

Figure 4. Carriage frequency of alleles and rs1801131 genotypes of the MTHFR gene in patients with tension type headache (TTH) and migraine (M) vs control group.

\subsection{HTR2C gene}

A statistically significant association of heterozygous carriage of the CG SNV rs6318 genotype of the HTR2C gene, which predetermines an increase in the affinity of the serotonin receptor, with the development of $\mathrm{M}(\mathrm{OR} 3.64 ; 95 \% \mathrm{CI} 1.27-10.49 ; \mathrm{p}=0.013)$ was shown (Fig. 5). At the same time, no associations of $\mathrm{M}$ with the carriage of the major allele $\mathrm{C}$ were found $(\mathrm{p}=0.594)$.

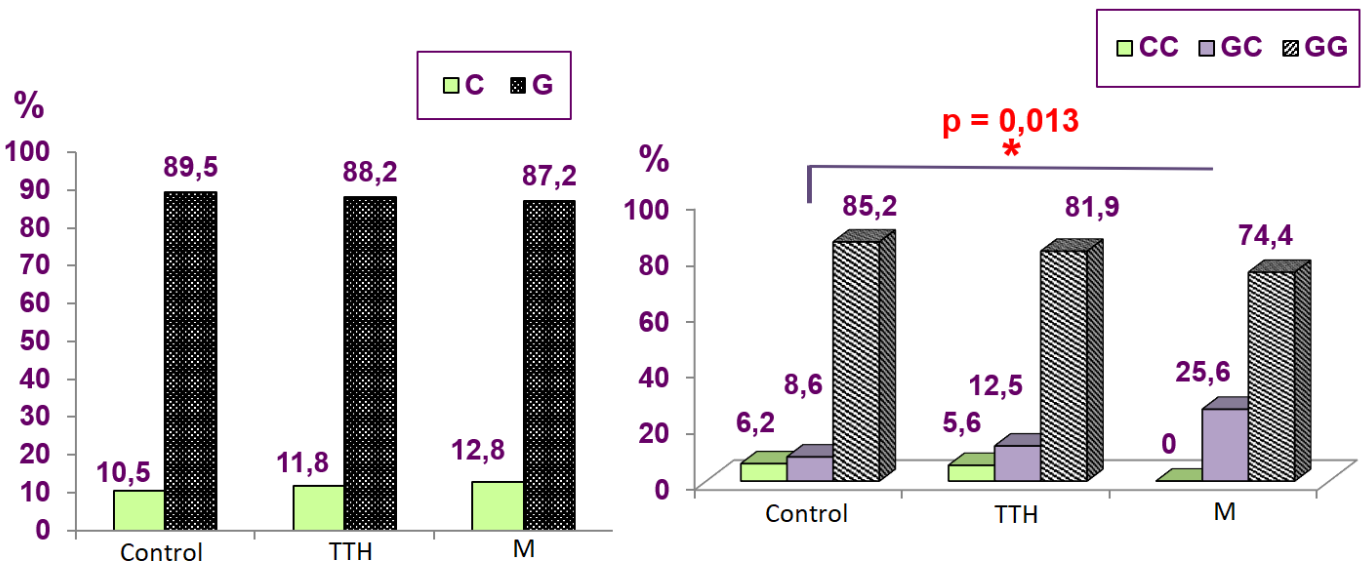

Figure 5. Carriage of rs6318 HTR2C gene alleles and genotypes in patients with tension type headache (TTH) and migraine (M) vs control group.

Carriage of the GC genotype of the HTR2C gene is a risk factor for the development of M (Fig. 6). 


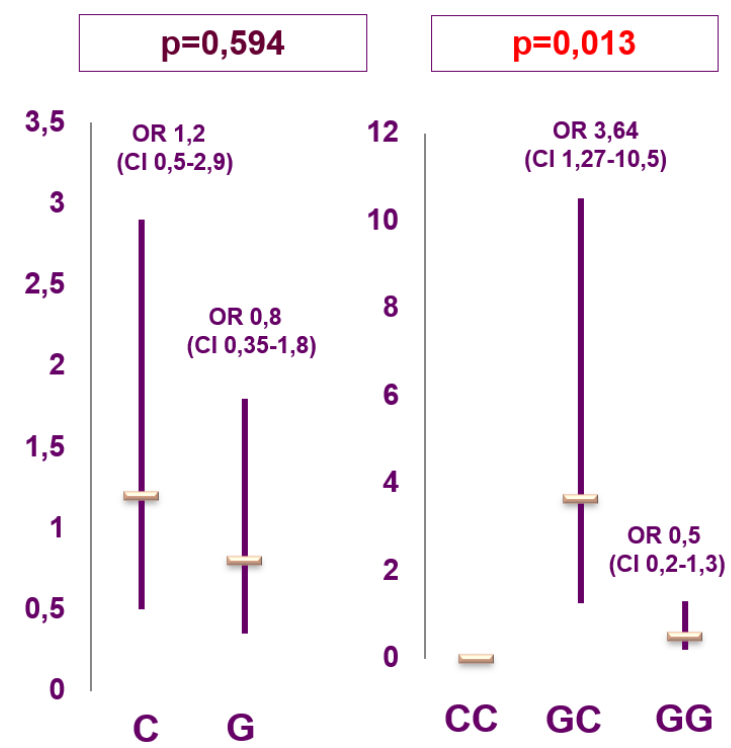

Figure 6. Odds ratio (OR) and 95\% confidence interval (CI) of the frequencies of alleles and genotypes rs6318 $(\mathrm{C}>\mathrm{G})$ for the development of migraine $(\mathrm{M})$.

Carriage of both alleles $(p=0.716)$ and genotypes $(p=0.736)$ rs6318 was not associated with the presence of TTH. It was shown that there were no statistically significant associations of primary headache in adults with the carriage of variant alleles and genotypes of other studied SNVs ( $p>0.05)$.

\section{Discussion}

The enzyme MTHFR catalyzes the conversion of 5,10-methylenetetrahydrofolate to 5-methyltetrahydrofolate. 5-methyltetrahydrofolate is an active form of folic acid required for the formation of methionine from homocysteine and then S-adenosylmethionine, which plays a key role in the process of DNA methylation. Rs1801133 (G677A) missense mutation A222V (alanine is exchanged for valine). Carriage of the 677A allele significantly reduces the enzyme activity to a level of $35 \%$ of the norm, as well as the level of folate. Rs1801131 (T1298G) - missense mutation E429A (glutamate is changed to alanine). Carriage of the $1298 \mathrm{G}$ allele moderately reduces the enzyme activity to $60 \%$ of the norm. This leads to an increase in blood homocysteine levels and a decrease in the pain threshold.

The 5-hydroxytryptophan receptor HTR2C is a serotonin receptor in the central nervous system. There is a connection between the frequency, intensity, and chronicity of headache with the level of serotonin in the blood. And also, the degree of its binding to serotonin receptors. Carriage of the minor allele rs6318 (68G>C) of the HTR2C gene leads to an increase in receptor activity, associated with hyperactivity of the hypothalamic-pituitary-adrenal system and an increase in the level of cortisol in the blood serum.

\section{Conclusions}

Carriage of the A allele (OR 1.77; 95\% CI 1.09-2.89) and the GA genotype (OR 2.24; 95\% CI 1.17-4.29) rs1801133 of the MTHFR gene is a risk factor for the development of TTH ( $\mathrm{p}<0.05$ ). Carriage of the A allele rs 1801133 of the MTHFR gene is a risk factor for the development of M (OR 1.97; 95\% CI 1.08-3.57; $\mathrm{p}<0.05)$. Carriage of the $\mathrm{G}$ variant allele and the rs1801131 GT and GG genotypes associated with reduced activity of the MTHFR enzyme does not affect the development of primary headache. In the control group, the 
prevalence of the $T$ allele associated with normal enzymatic activity was noted $(p=0.024)$. Carriage of the heterozygous genotype CG SNV rs6318 of the HTR2C gene associated with hyperactivity of the hypothalamic-pituitary-adrenal system and increases the risk of $\mathrm{M}$ by 3.6 times.

Author Contributions: Conceptualization, A.V.K., N.A.S. and A.V.S.; methodology, A.V.K., D.V.D. and S.N.Z.; software, V.V.T. and S.N.Z.; validation, A.V.K., V.V.T. and E.E.V.; formal analysis, A.V.K., S.N.Z and A.V.S.; investigation, A.V.K., N.A.S., V.V.T., D.V.D. and S.N.Z.; data curation, M.M.P., E.A.K. and D.S.K.; writing-original draft preparation, A.V.K., N.A.S., V.V.T. and S.N.Z.; writing - review and editing, A.V.K., N.A.S. and A.V.S.; visualization, V.V.T. and S.N.Z.; supervision, M.M.P. and R.F.N.; project administration, V.V.T. and E.E.V. All authors have read and agreed to the published version of the manuscript.

Funding: This research received no external funding.

Informed Consent Statement: Informed consent was obtained from all subjects involved in the study.

Acknowledgments: The authors express their gratitude to Evgeny A. Trefilov for preparing all figures.

Conflicts of Interest: The authors declare no conflict of interest.

\section{References}

1. Kondratev, A.V.; Shnayder, N.A.; Shulmin, A.V. Epidemiology of headaches. Modern problems of science and education 2015, 6. (in Russian)

2. Kondratev, A.V.; Shnayder, N.A.; Shulmin, A.V.; Lomakin A.I. Predictors of primary headaches. Problems of women health 2016, 1, 2-44 (in Russian).

3. Rainero, I.; Rubino, E.; Paemeleire, K.; Gai, A.; Vacca, A.; De Martino, P.; Gentile, S.; Sarchielli, P.; Pinessi, L. Genes and primary headaches: discovering new potential therapeutic targets. J. Headache Pain. 2013, 12, 14-61, doi:10.1186/1129-237714-61.

4. Li, X.; Zhou, X.; Peng, Y.; Liu, B.; Zhang, R.; Hu, J.; Yu, J.; Jia, C.; Sun, C. Network based integrated analysis of phenotypegenotype data for prioritization of candidate symptom genes. Biomed. Res. Int. 2014, 2014, 43-58, doi:10.1155/2014/435853.

5. Dux, M.; Sántha, P.; Jancsó, G. The role of chemosensitive afferent nerves and TRP ion channels in the pathomechanism of headaches. Pflugers Arch. 2012, 464, 239-248, doi: 10.1007/s00424-012-1142-7.

6. Rossi, C.; Pini, L.A.; Cupini, M.L.; Calabresi, P.; Sarchielli, P. Endocannabinoids in platelets of chronic migraine patients and medication-overuse headache patients: relation with serotonin levels. Eur J Clin Pharmacol. 2008, 64, 1-8, doi: 10.1007/s00228-007-0391-4.

7. Tomaz de Magalhães, M.; Núñez, S.C.; Kato, I.T.; Ribeiro, M.S. Light therapy modulates serotonin levels and blood flow in women with headache. A preliminary study. Experimental Biology and Medicine (Maywood, N.J.), 2015, 241, 40-45, doi: $10.1177 / 1535370215596383$.

8. Vashadze, Sh.V.; Sardzhveladze, N.M. Relationship between serum blood serotonin and tension--type headache. Georgian Med News. 2009, 171, 44-47 (in Russian).

9. Antonaci, F.; Ghiotto, N.; Wu, S; Pucci, E.; Costa, A. Recent advances in migraine therapy. SpringerPlus 2016, 5, 637, doi:10.1186/s40064-016-2211-8.

10. Demarquay, G.; Lothe, A.; Royet, J.P.; Costes, N.; Mick, G.; Mauguière, F.; Ryvlin, P. Brainstem changes in 5-HT1A receptor availability during migraine attack. Cephalalgia 2011, 31, 84-94, doi:10.1177/0333102410385581.

11. Yücel, Y.; Coşkun, S.; Cengiz, B.; et al. Association of Polymorphisms within the Serotonin Receptor Genes 5-HTR1A, 5HTR1B, 5-HTR2A and 5-HTR2C and Migraine Susceptibility in a Turkish Population. Clin Psychopharmacol Neurosci. 2016, 14, 250-255, doi:10.9758/cpn.2016.14.3.250. 
12. Oterino, A.; Castillo, J.; Pascual, J. et al. Genetic association study and meta-analysis of the HTR2C Cys23Ser polymorphism and migraine. J Headache Pain 2007, 8, 231-235, doi:10.1007/s10194-007-0399-2.

13. Tadtaeva, Z.G. Genetics of migraine (review). Bulletin of St. Petersburg State University. Series 11. Medicine. 2013, 1, 70-80 (in Russian).

14. Joutel, A.; Bousser, M.G.; Biousse, V.; La- bauge, P.; Chabriat, H.; Nibbio, A.; Maciazek, J.; Meyer, B.; Bach, M.A.; Weissenbach, J. A gene for familial hemiplegic migraine maps to chromosome 19. Nat. Genet. 1993, 5, 40-45.

15. Ophoff, R.A.; Terwindt, G.M.; Vergouwe, M.N.; van Eijk, R.; Mohrenweiser, H.; Litt, M.; Hofker, M.H.; Haan, J.; Ferrari, M.D.; Frants, R.R. A 3-Mb region for the familial hemiplegic migraine locus on 19p13.1-p13.2: exclusion of PRKCSH as a candidate gene. Dutch Migraine Genetic Research Group. Eur. J. Hum. Genet. 1996, 4, 321-328.

16. May, A.; Ophoff, R.A.; Terwindt, G.M.; Urban, C.; van Eijk, R.; Haan, J.; Diener, H.C.; Lindhout, D.; Frants, R.R.; Sandkuijl, L.A. Familial hemiplegic migraine locus on 19p13 is involved in the common forms of migraine with and without aura. Hum. Genet. 1995, 604-608.

17. Terwindt, G.M.; Ophoff, R.A.; van Eijk, R.; Vergouwe, M.N.; Haan, J.; Frants R.R.; Sandkuijl L.A.; Ferrari M.D.; Dutch Migraine Genetics Research Group. Involvement of the CACNA1A gene containing region on 19p13 in migraine with and without aura. Neurology 2001, 56, 8, 1028-1032, doi:10.1212/wnl.56.8.1028.

18. Kors, E.E.; Vanmolkot, K.R.; Haan, J.; Frants, R.R.; van den Maagdenberg, A.M.; Ferrari, M.D. Recent findings in headache genetics. Curr Opin Neurol. 2004, 17, 3, 283-288, doi:10.1097/00019052-200406000-00008.

19. Russell, M.B.; Ducros, A. Sporadic and familial hemiplegic migraine: pathophysiological mechanisms, clinical characteristics, diagnosis, and management. Lancet Neurol. 2011, 10, 457-470, doi: 10.1016/S1474-4422(11)70048-5.

20. Kopishinskaja, S.V.; Gustov, A.V. Genetic aspects of migraine. Zhurnal nevrologii i psikhiatrii imeni S.S. Korsakova. 2015, 115, 7, 124-129 (in Russian).

21. Ducros, A. Genetics of migraine. Rev. Neurol. (Paris). 2013, 169, 5, 360-371, doi: 10.1016/s1474-4422(02)00134-5.

22. Russell, M.B.; Levi, N.; Kaprio, J. Genetics of tension-type headache: a population based twin study. Am. J. Med. Genet. B. Neuropsychiatr. Genet. 2007, 144B, 982-986, doi: 10.1002/ajmg.b.30497.

23. Russell, M.B. Genetics of tension-type headache. J. Headache Pain. 2007, 8, 71-76, doi: 10.1007/s10194-007-0366-y.

24. Gaul, C.; Holle-Lee, D.; Straube, A. Botulinum toxin type A in headache treatment: Established and experimental indications. Nervenarzt. 2016, 87, 853-859, doi: 10.1007/s00115-016-0138-5.

25. Edgnülü, T.G.; Özge, A.; Erdal, N.; Kuru, O.; Erdal, M.E. Association analysis of the functional MAOA gene promoter and MAOB gene intron 13 polymorphisms in tension type headache patients. Adv. Clin. Exp. Med. 2014, 23, 901-906, doi: $10.17219 /$ acem/37333.

26. The International Classification of Headache Disorders 3rd edition, ichd-3.org. 